\title{
8D- $\delta^{18} \mathrm{O}$ RELATIONSHIPS AND THE THERMAL HISTORY OF BASAL ICE NEAR THE MARGINS OF TWO GLACIERS IN LYNGEN, NORTH NORWAY
}

\author{
By J.E. GorDon, \\ (Nature Conservancy Council, Northminster House, Peterborough PE1 IUA, England) \\ W.G. DarLing, \\ (Hydrogeology Group, British Geological Survey, Wallingford OX10 8BB, England) \\ W.B. WhaLLEy, \\ (Department of Geography, Queen's University, Belfast BT7 1NN, Northern Ireland) \\ and A.F. Gellatly
}

(Department of Geographical Sciences, Plymouth Polytechnic, Drake Circus,

Plymouth PL4 8AA, England)

\begin{abstract}
When plotted on a $\delta D^{-} \delta^{18} \mathrm{O}$ diagram, the isotope values of basal ice formed by refreezing of melt water beneath the cold-based margin of a corrie glacier lie on a straight line with a slope of 5.5. This freezing slope differs from a slope of 7.2 for the basal ice layer of the cold-based ice cap, Balgesvarri, which has not undergone refreezing. The latter slope is similar to that of 7.7 for the local precipitation. Co-isotope measurements from the two glaciers support the association of subglacial debris entrainment with refreezing processes.
\end{abstract}

\section{INTRODUCTION}

Subglacial thermal conditions have a fundamental bearing on processes of erosion and debris entrainment, and on resulting land-form patterns in the marginal zones of glaciers (e.g. Weertman, 1961; Boulton, 1972; Menzies, 1981). Recent theoretical and empirical studies have demonstrated the value of combined $6 D$ and $\delta^{18} \mathrm{O}$ measurements in interpreting the thermal history of glacier ice (Jouzel and Souchez, 1982; Souchez and Jouzel, 1984; Lorrain and Demeur, 1985; Souchez and de Groote, 1985; Sugden and others, 1987). In particular, since water undergoes isotopic fractionation on freezing, it is possible to distinguish unmodified glacier ice from basal ice which has undergone refreezing. On a $\delta D-\delta^{18} \mathrm{O}$ diagram, the isotopic values for precipitation generally plot on a straight line with a slope of about 8, the world meteoric line (Craig, 1961; Dansgaard, 1964), as does glacier ice that has not undergone phase changes. Ice which has undergone refreezing demonstrates a different slope, the magnitude depending on the intial $\delta$ values of the melted ice at the beginning of refreezing (Jouzel and Souchez, 1982; Souchez and Jouzel, 1984; Souchez and de Groote, 1985).

The aim of this note is to report the results of combined $\delta \mathrm{D}$ and $\delta^{18} \mathrm{O}$ measurements from two glaciers in maritime north Norway and their implications for the thermal history of the ice and observed variations in debris entrainment. One of the glaciers is a cold-based ice cap. The other, a corrie glacier, is probably warm-based but has a front margin that is subject to a strong winter cooling effect, a product of which is the freezing of fluted till on to the sole of the glacier.

\section{STUDY AREA}

The southern Lyngen peninsula (lat. $70^{\circ} \mathrm{N}$.; long. $20^{\circ} \mathrm{E}$.) contains a range of glacier types including small plateau ice caps, corrie, and valley glaciers (Gellatly and others, 1986; Gordon and others, 1987). Balgesvarri (1625 m a.s.1.) (Fig. 1) is a plateau ice cap at the head of Lyngsdalen c. $0.6 \mathrm{~km}^{2}$ in area and about $60 \mathrm{~m}$ thick. Recent net annual accumulation measured in summit snow pits is less than $1 \mathrm{~m} \mathrm{a}^{-1}$ (water equivalent). Excavations at the ice edge have revealed that the margin of the ice cap is frozen to the underlying block field and that no debris is entrained in the basal ice layers (Whalley and others, 1981). Estimates of basal ice temperatures using a simple column model (Budd and others, 1971) for the accumulation area and a modification of the Robin model for the ablation area (Robinson, 1984) suggest that the entire ice cap is cold-based. In summer, permafrost exists at a depth of $0.6-0.7 \mathrm{~m}$ beneath the surface of nearby ice-free block fields.

"Flutes Glacier" (an informal name) is a $1.4 \mathrm{~km}$ long corrie glacier extending from about $800 \mathrm{~m}$ to $1050 \mathrm{~m}$ a.s.1. on the south side of Sydbreen in Lyngsdalen (Fig. 1). Fluted till occurs extensively in the glacier forefield. Immediately in front of the glacier it is frozen and can be traced back beneath the glacier as a single debris layer frozen on to clean glacier ice above. Where melted out in the glacier forefield, the fluted till layer is typically $0.3-0.8 \mathrm{~m}$ thick but locally exceeds $1.5 \mathrm{~m}$. The presence of the fluted till, generally believed to form under warm-based ice (Boulton, 1976), suggests that "Flutes Glacier" has a warm-based sector up-glacier from a cold-based margin. Estimates of basal ice temperatures using a modification of the Robin model (Robinson, 1984) support this inference.

Temperature measurements have not been made at the glaciers. At Lyngseidet ( $3 \mathrm{~m}$ a.s.l.), $16 \mathrm{~km}$ north-east from Lyngsdalen, mean annual temperature is $+3.3^{\circ} \mathrm{C}$; mean 

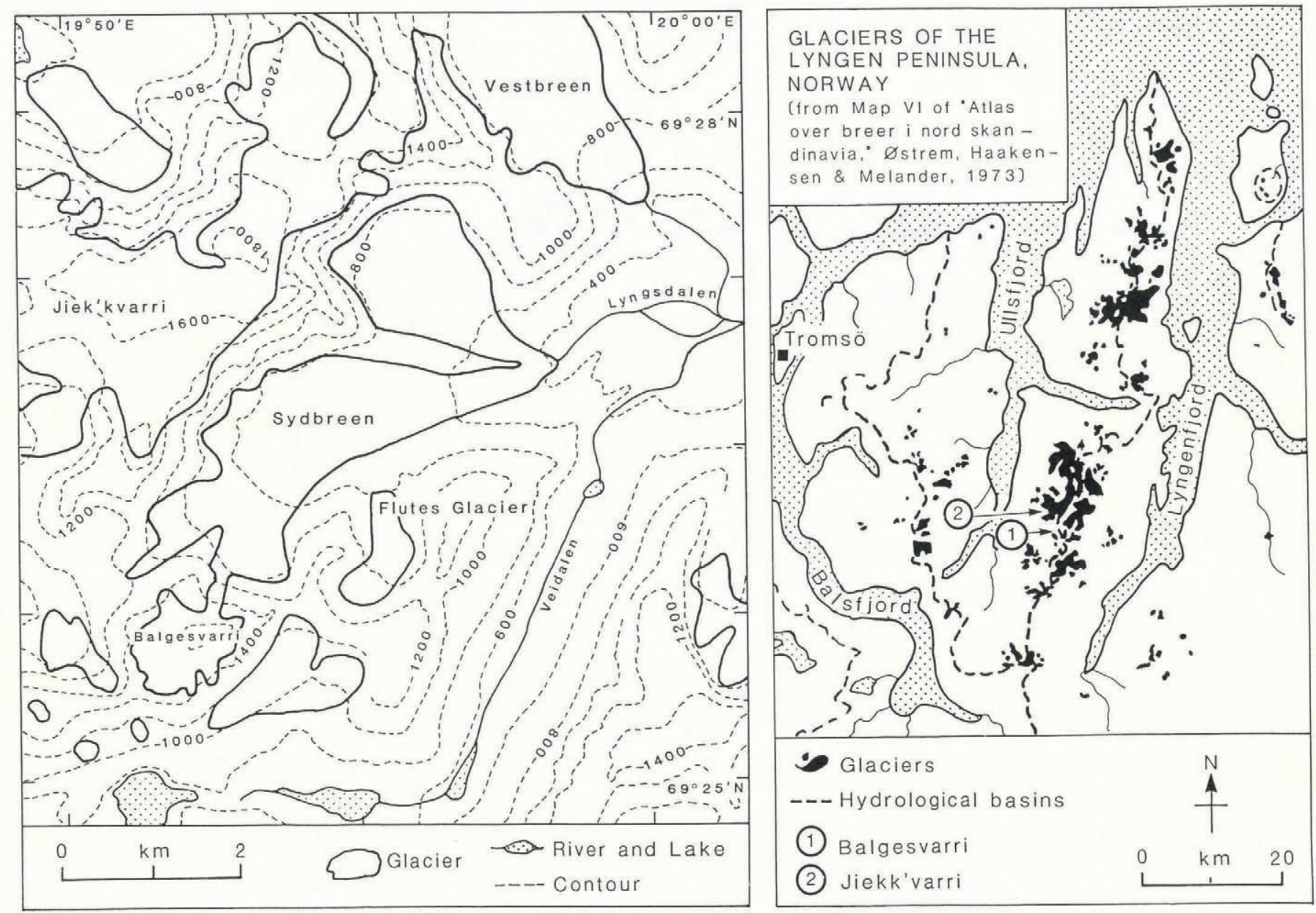

Fig. 1. Location maps.

January temperature, $-3.6^{\circ} \mathrm{C}$; and mean July temperature, $+13.2^{\circ} \mathrm{C}$ (1931-60 standard normals). Assuming a lapse rate of $0.5^{\circ} \mathrm{C} / 100 \mathrm{~m}$ (Laaksonen, 1976), estimated mean annual temperatures at "Flutes Glacier" are $-0.7^{\circ}$ to $-0.2^{\circ} \mathrm{C}$ and at Balgesvarri summit, $-4.8^{\circ} \mathrm{C}$.

\section{SAMPLE COLLECTION AND ANALYSIS}

Samples were collected from (1) the basal ice layer of Balgesvarri; (2) the basal debris layer of "Flutes Glacier", comprising the fluted till frozen to the glacier sole (samples were collected from this layer laterally across the ice front and not in a vertical stratigraphical profile); (3) surface glacier ice and surface melt water in the area between the ice front and transient snow line on "Flutes Glacier"; (4) snow from the 1984-85 winter above the transient snow line and from snow banks in the forefield of "Flutes Glacier"; (5) permafrost in a block field adjacent to Balgesvarri ice cap; (6) summer 1985 rainfall. Where the source material was exposed to the air, the surface $10-15 \mathrm{~cm}$ was removed prior to sampling. Samples were collected in polythene bags, sealed, and allowed to melt completely in the shade before being transferred to polypropylene vials with screw caps which were sealed with wax.

Oxygen and hydrogen stable-isotope ratios were measured on a VG-Micromass G02E mass spectrometer. Carbon dioxide for ${ }^{18} \mathrm{O}$ measurement was prepared by the standard method of equilibration at $25^{\circ} \mathrm{C}$ with $5 \mathrm{ml}$ sample aliquots, while hydrogen for $\delta D$ measurement was prepared by reduction of $10 \mu \mathrm{l}$ aliquots with zinc metal at $450^{\circ} \mathrm{C}$ (Coleman and others, 1982). Precision is considered to be better than $\pm 0.2 \% \circ \delta^{18} \mathrm{O}$ and $\pm 2 \% 08 \mathrm{D}$.

\section{RESULTS AND INTERPRETATION}

For rain and snow from the area of "Flutes Glacier", 8D values range between -72 and $-127 \%$, with an unweighted mean value of $-89.4 \% 0^{\circ} ; \delta^{18} \mathrm{O}$ values, between -10.4 and $-17.5 \%$, with an unweighted mean value of $-12.8 \%$. The latter compares with a mean figure of $-13.3 \%$ for four samples of fresh spring snow collected at altitudes between 760 and $1280 \mathrm{~m}$ on Charles Rabots Bre in the Okstindan mountains (lat. $66^{\circ} \mathrm{N}$.; long. $14^{\circ} \mathrm{E}$.) $450 \mathrm{~km}$ to the south of Lyngen (Hambrey, 1974). The mean $\delta^{18} \mathrm{O}$ value and the estimated mean annual air temperature $\left(-2^{\circ} \mathrm{C}\right)$ broadly correspond with the linear relationship demonstrated between these two variables by Dansgaard (1964, fig. 3).

When plotted on a $8 \mathrm{D}-\delta^{18} \mathrm{O}$ diagram (Fig. 2), the rain and snow measurements show a linear relationship defined by the least-squares regression line, $\delta \mathrm{D}=7.72 \delta^{18} \mathrm{O}+9.66$ $\left(r^{2}=0.99\right.$; standard error of estimate $\left.=1.77 \% 0\right)$. This line is considered to represent the local meteoric line.

The $\delta D$ and $\delta^{18} \mathrm{O}$ values from the basal ice of Balgesvarri ice cap plot on a line with the form $\delta \mathrm{D}=$ $7.15 \delta^{18} \mathrm{O}+2.49 \quad\left(r^{2}=0.99 ;\right.$ standard error of estimate $=0.59 \%$ ) which closely approximates the slope of the local meteoric line. This demonstrates that the ice has not undergone melting-refreezing processes during its transfer from the accumulation area to its position at the base of the glacier near the ice margin. However, the isotopic values from the basal debris layer of "Flutes Glacier" lie on a straight line with a different slope defined by the least-squares regression, $\delta \mathrm{D}=5.45 \delta^{18} \mathrm{O}-14.41 \quad\left(r^{2}=0.95\right.$; standard error of estimate $=2.79 \%$ ). The slope of this line is typical of that arising from a freezing or melting-refreezing process under closed system conditions (Jouzel and Souchez, 1982; Souchez and Jouzel, 1984; Souchez and de Groote, 1985). The initial composition of the parent waters is normally defined by the intersection of the freezing line with the meteoric line (Jouzel and Souchez, 1982; Souchez and Jouzel, 1984), in this case $\delta D=-72.2 \% \circ$ and $\delta^{18} \mathrm{O}=-10.6 \%$. However, with one exception, all of the samples measured in this study are relatively lighter than this value. We therefore suggest an initial composition defined by the mean values of the 


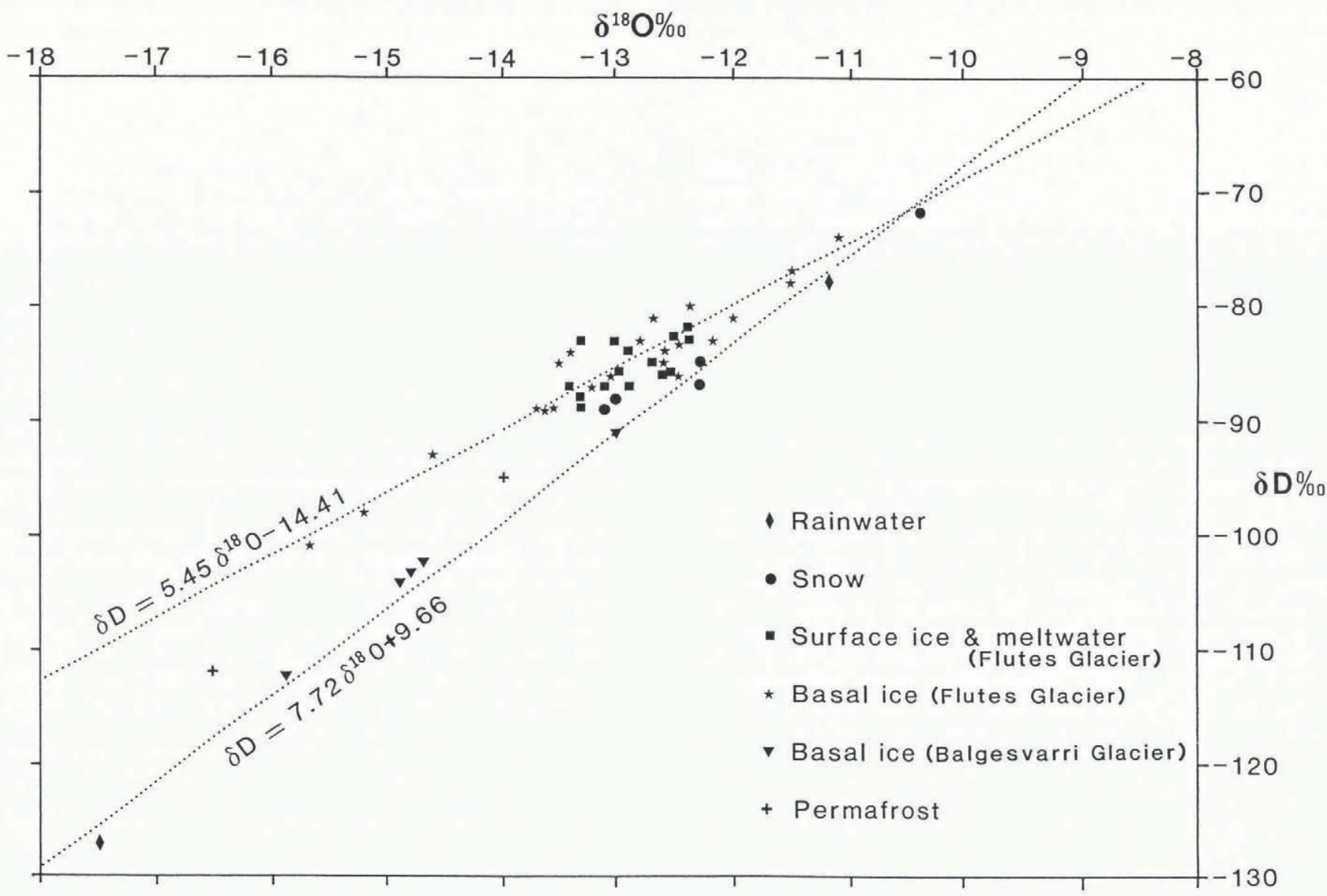

Fig. 2. $\delta D-\delta^{18} O$ diagram for Lyngen ice and precipitation samples.

surface-ice and melt-water samples: $\delta D=-85.3 \%$ and $8^{18} \mathrm{O}=-12.9 \%$. These values lie within the area of intersection of the $95 \%$ confidence limits of the two regression lines. Using the model of Jouzel and Souchez (1982), the theoretical slope for the evolution during freezing of parent waters with this composition would be 5.7 or 6.4 using the two somewhat different equilibrium fractionation factors employed by Jouzel and Souchez (1982) and Souchez and Jouzel (1984). The slope of 5.5 measured in this study is close to the first figure and, particularly in view of the spread in experimental determinations of icewater isotopic fractionation factors (Moser and Stichler, 1980 ), is therefore considered to be in good agreement with the Jouzel-Souchez model.

The surface-ice and melt-water samples appear to be relatively depleted in ${ }^{18} \mathrm{O}$ compared with the local rainwater and snow (Fig. 2). However, it is not clear if this is a real effect or a function of sampling error, and we have not investigated for any isotopic changes during the transformation of snow to glacier ice. If the surface-ice and meltwater measurements are combined with those for the rain and snow to calculate the local precipitation slope, the relationship is $6 \mathrm{D}=7.49 \delta^{18} \mathrm{O}+9.92 \quad\left(r^{2}=0.91 ;\right.$ standard error of estimate $=3.25 \%$ ). The intersection of the freezing slope with this line is at $\delta \mathrm{D}=-79.5 \%_{0}$ and $\delta^{18} \mathrm{O}=-11.9 \%_{0}$, which again lies to the right of the main cluster of points on Figure 2. For parent water of this composition, the calculated freezing slope is 6.5 or 5.8 , depending on which deuterium fractionation factor is used.

If the overlap in isotopic composition of the surface ice and melt water with the basal ice is a real effect and the points all lie on the same refreezing line, this raises the question of the extent to which the isotopic characteristics of the "Flutes Glacier" ice, both surface and basal, may have been determined by refreezing near the glacier surface during the transformation from snow to glacier ice. Further work is required to resolve this question.

The two permafrost samples from Balgesvarri plot between the local meteoric line and the freezing line for the basal ice samples from "Flutes Glacier" (Fig. 2). It is difficult to assess the significance of only two samples but their composition may reflect fractionation during freezing of precipitation that has percolated through the surface block field to the top surface of the permafrost layer.

\section{CONCLUSIONS}

The basal ice layers of Balgesvarri and "Flutes Glacier" are distinguished by their combined $\delta \mathrm{D}-\delta^{18} \mathrm{O}$ signatures. On a $\delta D-\delta^{18} \mathrm{O}$ diagram, measurements from Balgesvarri plot close to the local meteoric line, confirming that the basal ice, which is free of debris, has not undergone refreezing and that the ice cap is cold-based. Measurements from the basal, debris-rich ice of "Flutes Glacier" plot on a straight line with a slope of 5.5, which indicates the operation of melting-refreezing processes. While we are not able to determine conclusively from the isotopic evidence the extent to which the latter occurred near the glacier surface during the transformation from snow to ice and/or subsequently at the glacier bed, the effective entrainment of the fluted till suggests the presence of a warm-based zone up-glacier from the cold-based margin.

Our results lend support to the empirical and theoretical conclusions of Jouzel and Souchez (1982) and Souchez and Jouzel (1984), and demonstrate some of the potential of using combined $\delta D$ and $\delta^{18} \mathrm{O}$ measurements for interpreting the thermal history of basal ice and subglacial processes, including debris entrainment. The two examples studied here support the association of debris entrainment with subglacial refreezing processes. However, in further isotopic studies of the thermal history of basal ice, it would be useful to evaluate the possible contribution of refreezing processes associated with the transformation of snow to ice in the accumulation areas of low-altitude, sub-polar glaciers. 


\section{ACKNOWLEDGEMENTS}

We thank A. Lardner for the stable-isotope analyses. We are grateful to the Royal Society for financial support and to members of the British Schools Exploring Society for assistance in Lyngen. JEG also acknowledges a grant from the 20th International Geographical Congress Fund; WBW and AFG, support from Queen's University, Belfast. WGD contributes by permission of the Director, British Geological Survey (U.K. Natural Environment Research Council). We also thank Dr D.A. Peel for helpful comments.

\section{REFERENCES}

Boulton, G.S. 1972. The role of thermal régime in glacial sedimentation. In Price, R.J. and D.E. Sugden, comps. Polar geomorphology. London, Institute of British Geographers, 1-19. (Special Publication 4.)

Boulton, G.S. 1976. The origin of glacially fluted surfaces - observations and theory. J. Glaciol., 17(76), 287-309.

Budd, W.F., D. Jenssen, and U. Radok. 1971. Derived physical characteristics of the Antarctic ice sheet. $A N A R E$ Interim Rep., Ser. A (IV), Glaciology. (Publication 120.)

Coleman, M.L., T.J. Shepherd, J.J. Durham, J.E. Rouse, and G.R. Moore. 1982. Reduction of water with zinc for hydrogen isotope analysis. Anal. Chem., 54, 993-995.

Craig, H. 1961. Isotopic variations in meteoric waters. Science, 33(3465), 1702-1703.

Dansgaard, W. 1964. Stable isotopes in precipitation. Tellus, 16(4), 436-468.

Gellatly, A.F., W.B. Whalley, and J.E. Gordon. 1986. Topographic control over recent glacier changes in southern Lyngen peninsula, north Norway. Nor. Geogr. Tidsskr., 40(4), 211-218.

Gordon, J.E., W.B. Whalley, A.F. Gellatly, and R.I. Ferguson. 1987. Glaciers of the southern Lyngen peninsula, Norway. In Gardiner, V., ed. International geomorphology 1986. Part II. Chichester, etc., John Wiley and Sons, 743-758.

Hambrey, M.J. 1974. Oxygen isotope studies at Charles Rabots Bre, Okstindan, northern Norway. Geogr. Ann., $56 \mathrm{~A}(3-4), 147-158$.

Jouzel, J. and R.A. Souchez. 1982. Melting-refreezing at the glacier sole and the isotopic composition of the ice. $J$. Glaciol., 28(98), 35-42.

Laaksonen, K. 1976. The dependence of mean air temperatures upon latitude and altitude in Fennoscandia (1921-1950). Ann. Acad. Sci. Fenn., Ser. A3, 119.

Lorrain, R.D. and P. Demeur. 1985. Isotopic evidence for relic Pleistocene glacier ice on Victoria Island, Canadian Arctic Archipelago. Arct. Alp. Res., 17(1), 89-98.

Menzies, J. 1981. Freezing fronts and their possible influence upon processes of subglacial erosion and deposition. Ann. Glaciol., 2, 52-56.

Moser, H. and W. Stichler. 1980. Environmental isotopes in ice and snow. In Fritz, P. and J.C. Fontes, eds. Handbook of environmental isotope geochemistry. Vol. 1. New York, Elsevier, 141-171.

Robinson, P.H. 1984. Ice dynamics and thermal regime of Taylor Glacier, south Victoria Land, Antarctica. $J$. Glaciol., 30(105), 153-160.

Souchez, R.A. and J.M. de Groote. 1985. $\delta \mathrm{D}-\delta^{18} \mathrm{O}$ relationships in ice formed by subglacial freezing: paleoclimatic implications. J. Glaciol., 31(109), 229-232

Souchez, R.A. and J. Jouzel. 1984. On the isotopic composition in $6 \mathrm{D}$ and $\delta^{18} \mathrm{O}$ of water and ice during freezing. J. Glaciol., 30(106), 369-372.

Sugden, D.E., and 6 others. 1987. Evidence for two zones of debris entrainment beneath the Greenland ice sheet. Nature, 328(6127), 238-241.

Weertman, J. 1961. Mechanism for the formation of inner moraines found near the edge of cold ice caps and ice sheets. J. Glaciol., 3(30), 965-978.

Whalley, W.B., J.E. Gordon, and D.L. Thompson. 1981. Periglacial features on the margins of a receding plateau ice cap, Lyngen, north Norway. J. Glaciol., 27(97), 492-496. 